\title{
Isolated Pneumopericardium After Penetrating Chest
}

\section{Injury}

\author{
Hasan Ekim ${ }^{1 *}$, Meral Ekim $^{2}$ \\ ${ }^{1}$ Bozok University Faculty of Medicine Department of Cardiovascular Surgery, Yozgat \\ ${ }^{2}$ Bozok University Faculty of Health Sciences, Department of Emergency Aid and Disaster Management, Yozgat
}

\begin{abstract}
Pneumopericardium is defined as the presence of air or gas in the pericardial sac. Its course is stable unless tension pneumopericardium develops. However, even patients with asymptomatic pneumopericardium should be carefully monitored due to risk of tension pneumopericardium. We presented a 24-year-old male victim with stab wound complicated with isolated pneumopericardium. Pneumopericardium was accidentally encountered by plain chest radiograph. It was spontaneously resolved without pericardiocentesis or pericardial window.
\end{abstract}

Key Words: Pneumopericardium, Stab Wound, Isolated

\section{Introduction}

Pneumopericardium is defined as the presence of air or gas in the pericardial sac (1). It is commonly seen in neonates on mechanical ventilation and in victims sustaining blunt thoracic trauma (1). However, iatrogenic lesions such as barotrauma, endoscopic and surgical interventions may also lead to pneumopericardium. (2). A pneumopericardium due to penetrating thoracic trauma is also rare (1). We presented an interesting case of stab wound complicated with isolated pneumopericardium.

\section{Case Report}

A 24-year-old male patient was referred to our hospital for forensic report. He was injured with a stabbing instrument a week ago from the left side of his chest. Physical examination findings and routine laboratory tests were found to be normal. There was no subcutaneous emphysema. His chest radiograph revealed a pericardial linear density compatible with pneumopericardium (Figure 1). Pulmonary vascularity was normal and there was no pneumothorax. Electrocardiographic and echocardiographic examinations were found to be normal. Since he was asymptomatic, we decided not to perform any pericardial drainage procedure (pericardiocentesis or pericardial window). His clinical course was uneventful and pneumopericardium resolved spontaneously.

\section{Discussion}

Pneumopericardium is a rare complication of blunt or penetrating thoracic trauma and may also occur iatrogenically (3). In addition, pericardial infections may also lead to pneumopericardium (4). Lee et al (5) reported that the swinging movement of the drainage bottle may allow air in the bottom of the bottle to enter the chest tube and then into the pericardial space leading to pneumopericardium. Therefore, care should be taken when transporting patients undergoing pericardial drainage.

Isolated pericardial injuries as a result of stab wounds are very rare. Usually, this type of injury inevitably leads to the development of hemothorax or pneumothorax. However, adherence of the lung to the chest wall due to previous pulmonary infection may prevent the development of pneumothorax following a stab wound, as seen in our patient. In this circumstance, a combined stab wound of the visceral pleura and pericardium without cardiac injury may lead to pneumopericardium due to a bronchopericardial fistula (6).

A tendency to pneumopericardium may develop due to positive pressure ventilation in neonates with respiratory distress syndrome (7). Pneumopericardium in the newborn has also been reported to be associated with other air leak syndromes such as pneumothorax, pneumomediastinum, pneumoperitoneum, and interstitial and subcutaneous emphysema (7). Pneumopericardium should be differentiated from a pneumomediastinum. When the patient is in the lateral decubitus position, the air in 


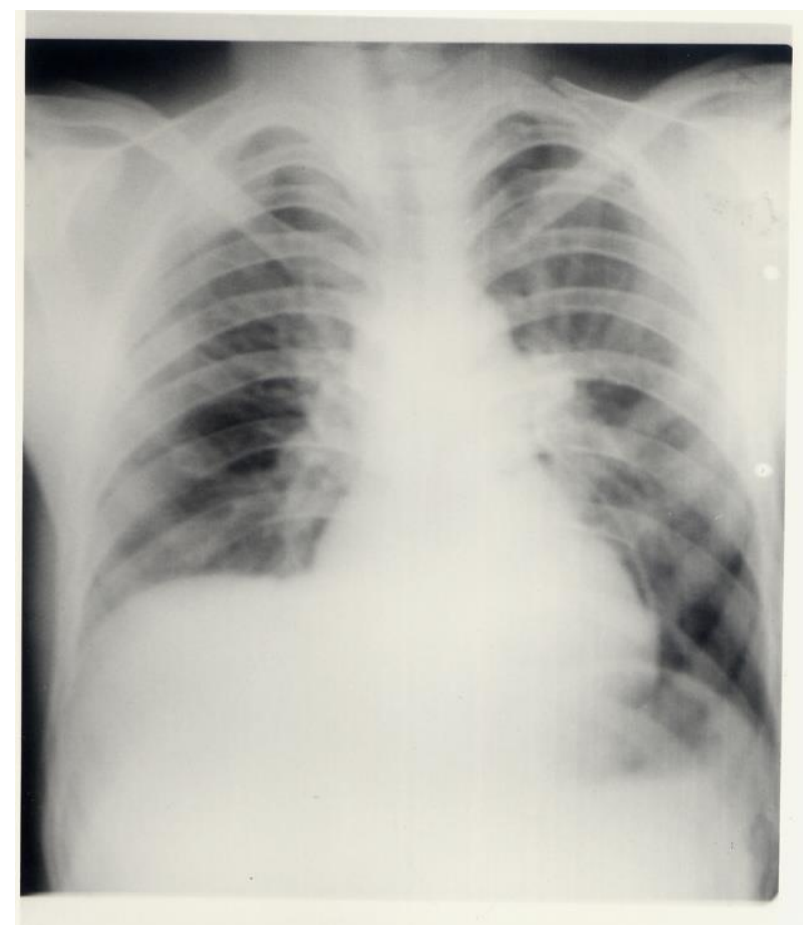

Fig. 1. Chest radiograph showing pneumopericardium without pneumothorax after a stabbing

the pericardial sac will shift, whereas air in the mediastinum usually will not move in the short time interval between radiograms (1,8). So, pneumomediastinum and pneumopericardium can be easily differentiated.

Usually, the main symptoms of pneumopericardium are chest pain and shortness of breath (5). However, an isolated pneumopericardium after chest trauma was reported to be very rarely symptomatic (9).

Although cardiac tamponade is most often caused by the accumulation of blood or other fluids in the pericardial space, it has been reported that pneumopericardium may cause cardiac tamponade (8). Even in patients with pneumopericardium who were initially stable status, tension pneumopericardium may develop (1). Therefore, patients with asymptomatic pneumopericardium may be closely monitored to avoid escalation to cardiac tamponade (10). Tension pneumopericardium leads to decreased cardiac output by inhibiting cardiac contractility and venous return to the heart (7). The air tamponade is likely to develop especially in ventilated patients and may occur most frequently in premature infants with respiratory distress syndrome or in adults with chest trauma (8). If there is a sudden decrease in the cardiothoracic ratio due to pneumopericardium, surgeons should be alert because of the possible risk of tension pneumopericardium and impending cardiac tamponade (1). Pericardial air should be evacuated emergently in patients with tension pneumopericardium (3). Failure to achieve rapid effective evacuation may cause cardiac arrest (3). Once upon a time, pneumopericardium was also used in the treatment of tuberculosis pericarditis. The rationale was that prevent the formation of exudates and the development of adhesions since the two pericardial layers will separate from each other due to air inside the pericardium (8).

The development of isolated pneumopericardium without hemothorax and/or pneumothorax after stab wound has been encountered very rarely. In patients with isolated pneumopericardium following stab wound, although pneumopericardium is usually spontaneously resolved, victims should be closely monitored due to possible risk of tension pneumopericardium.

\section{References}

1. Nicol AJ, Navsaria PH, Hommes M, Edu S, Kahn D. Management of a pneumopericardium due to penetrating trauma. Injury 2014; 49: 1368-1372.

2. Xu Y, Xu Z, Wang Y. Cardiac tamponade due to pneumopericardium. Pak J Med Sci 2014; 30: 924926.

3. Macgoey P, Schamm M, Degiannis E. Tension pneumopericaedium: case report. Ulus Travma Acil Cerrahi Derg 2010; 16: 477-479.

4. Abrahan Iv LL, Obillos SMO, Aherrera JAM, et al. A Rare Case of Pneumopericardium in the Setting of Tuberculous Constrictive Pericarditis. Case Rep Cardiol 2017; 2017: 4257452.

5. Lee J, Kang BS, Kim C, Choi J. Tension pneumopericardium after pericardiocentesis. J Korean Med Sci 2016; 31: 470-472.

6. Gould JC,and Schurr MA. Tension pneumopericardium after blunt chest trauma. Ann Thorac Surg 2001; 72: 1728-1730.

7. Roychoudhury S, Kaur S, Soraisham AS. Neonatal Pneumopericardium in a Nonventilated Term Infant: A Case Report and Review of the Literature. Case Rep Pediatr 2017; 2017: 3149370.

8. Cummings RG, Wesly RL, Adams DH, Lowe JE. Pneumopericardium resulting in cardiac tamponade. Ann Thorac Surg 1984; 37: 511-518.

9. Demetriades D, Levy R, Hatzitheofilou C, Chun R. Tension pneumopericardium following penetrating trauma: case report. J Trauma 1990; 30: 238-239.

10. Al-Taweel A, Ayub A, Huang CY, Rehmani S, AlAyoubi A, Bhora FY. Pneumopericardium Leading to Cardiac Tamponade in a Patient with Lung Cancer. Thorac Cardiovasc Surg Rep 2016; 5: $13-15$ 